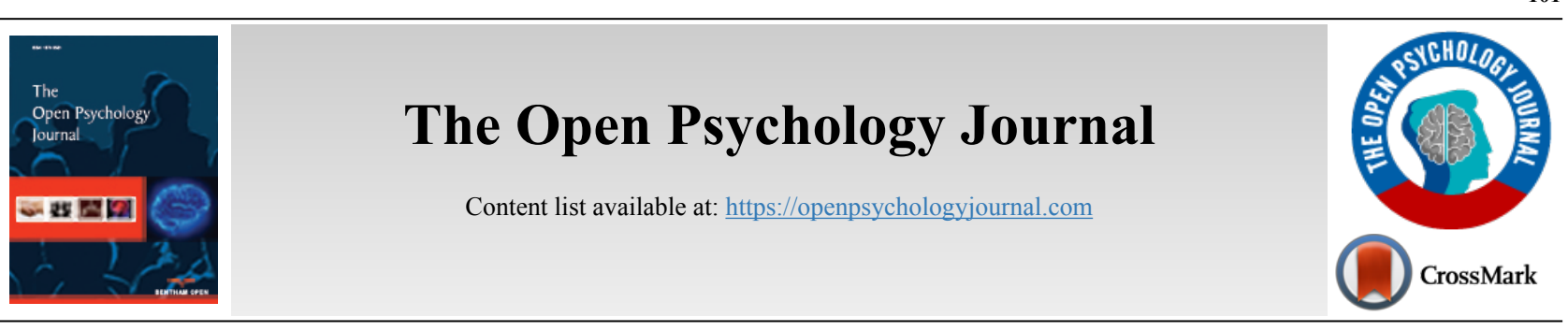

RESEARCH ARTICLE

\title{
The Relationship Between Personality Traits and Coping Strategies in a Sample of Siblings of People With and Without Intellectual Disability: The Mediating Role of Sibling Relationship Quality
}

\author{
Dawid K. Scigala ${ }^{1}$, Matteo A. Fabris ${ }^{2}$ and Claudio Longobardi ${ }^{2, *}$ \\ ${ }^{1}$ Institute of Psychology, Faculty of Applied Social Sciences, The Maria Grzegorzewska University, Warsaw, Poland \\ ${ }^{2}$ Department of Psychology, University of Turin, Torino, Italy
}

\begin{abstract}
:
Background:

The quality of sibling relationships is an important factor in the development of individuals, particularly in the context of a relationship with a brother or sister with disabilities.

Aims:

This research aims to assess the moderating role of the quality of the relationship with siblings between personality traits and coping strategies.

Methods:

The participants were 187 adults, of whom 97(51.9\%) were Individuals with brothers or sisters with intellectual disabilities (S-IDs), aged 18 to 60 years $(\mathrm{M}=30.22 ; \mathrm{SD}=12.17)$. The second group was 90 (48.1\%) Individuals with typical developmental siblings (S-TDs) aged 18 to 76 years $(\mathrm{M}=28.56$; $\mathrm{SD}=11.66)$. Respondents completed the Big Five Questionnaire (BFQ), the Coping Orientation to Problem Experiences (COPE), and the Adult Sibling Relationships Questionnaire (ASRQ).

Results:

The data show a correlation between personality traits and coping strategies. In addition, the size of the ASRQ was found to moderate the relationship between personality traits and coping strategies, albeit in a different way between the two groups.

Conclusion:

The quality of the reality with brothers or sisters turns out to be an important factor in the development, and it is found to mediate the relationship between personality traits and the development of coping strategies, both in S-TDs and S-IDs, presenting similarities and differences. Future research guidelines have been discussed.
\end{abstract}

Keywords: Siblings, Personality traits, Quality of sibling relationship, Coping strategies, Intellectual disability, Meditating role.

\section{Article History} Received: November 27, 2019

Revised: April 21, 2020

Accepted: May 08, 2020

\section{INTRODUCTION}

Brother and sisters play an important role in an individual's development [ 1 - 3] and the relationship with them is often the one that lasts the longest during an individual's life [2]. The way in which they interact with siblings and the quality of the relationship with them can influence different aspects of the psychological development, adjustment, and

\footnotetext{
* Address correspondence to this author at the Department of Psychology, Università degli studi di Torino, Torino, Italy;

E-mail: claudio.longobardi@unito.it
}

personality characteristics of individuals [4 - 6]. For example, the meta-analysis of Buist and colleagues [7] showed that more sibling warmth, less sibling conflict, and less differential treatment were all significantly associated with fewer psychological symptoms. Siblings can offer valuable support both in childhood and adulthood, but it is especially during the period of development that the quality of the relationship with siblings can influence the adaptation of the individual and the quality of his or her relationships in the future [3 - 5]. Although scholars have mainly focused on the observation of 
relationships between siblings in childhood, in recent decades, the literature has progressively examined the development of relationships between siblings in adulthood [3]. In this direction, a more positive attitude towards adult sibling relationships was found to be associated with more emotional stability and psychological wellbeing.

Relationships between siblings in adulthood tend to be based on less contact and closeness, less conflict, and more warmth [8, 9]; however, the bond between siblings can continue to be characterized by ambivalent emotional feelings even during adulthood [3]. While the relationship between siblings has an effect on the psychological development of individuals, some authors have questioned the development of individuals in the context of a relationship with an S-ID. An SID can be perceived as a significant source of stress when compared to an S-TD, and, also, depending on the particular characteristics of S-IDs, such as the degree of the disability, the level of independence, and the presence of behavioral disorders $[5,10$ - 13]. S-TDs growing up alongside S-IDs can, themselves, take on the care functions that are the responsibility of adult caregivers, taking on roles and responsibilities that are not appropriate for their age. By taking on this role, the development of the child can be negatively affected, and they can experience a reduction in psychological wellbeing and increased distress in adulthood and difficulties in social interactions [14]. In particular, females seem to be more prone to developing distress [5, 15]. Although not all studies agree [16], some evidence suggests that S-IDs tend to maintain less frequent and lower quality contact than S-TDs [17]. In this way, it is possible that different distressing factors intervene to decrease the quality of the relationship between S-TDs and SIDs compared to that of pairs of siblings with typical development. Some research has identified a correlation between the quality of the relationship between siblings with typical development and those with intellectual disability and the use of coping strategies $[5,10,14,18]$. "Coping strategies" refer to a person's active or passive strategies and behaviors for dealing with stressful events [19].

Traditionally, problem-focused coping strategies are considered more adaptive than emotion-focused strategies, as they tend to act directly on the problem. In contrast, emotionfocused strategies are characterized by avoidance or heightening of the emotional aspects of the situation and therefore considered more dysfunctional [19]. The literature tends to demonstrate an association between a better quality relationship with S-IDs and the use of more appropriate and adaptive coping strategies [5, 10, 14, 18]. Children [18] and adults [10] reported more frequent use of problem-focused coping strategies and less of emotion-focused coping strategies when reporting a closer sibling relationship, and with siblings with typical and atypical development. Recently, Prino and colleagues [5] found that women had an association between transcendent-oriented coping strategies and high scores in the quality of their relationships with siblings, whether TD or ID, while men reported less use of passive coping strategies when they had a higher-quality relationship with their ID brothers or sisters. Transcendent-oriented coping strategies refer to the use of religion and a scarce sense of humor. These kinds of coping strategies may be dysfunctional in the case of stress because they do not promote active coping strategies but might reinforce passiveness during difficulties [5].

However, the data available on the relationship between coping strategies and the quality of sibling relationships are rather scarce, and it is difficult to provide a comprehensive interpretation of the data available to us because of the different ways in which strategies have been theoretically conceptualized, described, classified, and measured in the research conducted so far $[5,20]$. From an evolutionary point of view, it is conceivable that the stressful experience of having a brother or sister with ID influences, in accordance with the quality of the relationship with his or her sibling, the development of coping strategies. These strategies, acquired during development in the family context and in the relationship with the ID brother or sister, are then maintained even in later periods of development, such as adulthood [5].

Generally speaking, coping can be conceptualized as a regulatory process that can reduce negative feelings derived from stressful experiences, such as growing up with a sibling with ID. The coping actions carried out by an individual in stressful situations can, therefore, be read as a dynamic personality process $[21,22]$, and different studies tend to report a correlation between personality traits and coping strategies [23 - 25]. In general, the emerging trend in literature is that of a positive association between adaptive personality traits and active coping strategies, while maladaptive personality traits, and especially neuroticism, are associated with avoidant coping strategies [23, 25]. It can, therefore, be assumed that individuals with dysfunctional personality traits have a greater vulnerability to stress due to the implementation of failed coping strategies. The five-factor model of personality (BF-5) turned out to be a useful context for assessing individual differences in coping strategies and their relationship to personality traits $[25,26]$. The BF-5 describes the personality of individuals according to a taxonomy that includes the following: neuroticism $(\mathrm{N})$, extraversion $(\mathrm{E})$, openness $(\mathrm{O})$, agreeableness (A), and conscientiousness (C) [18]. People with high neuroticism levels tend to be impulsive, more vulnerable to stress, and have negative affections. These individuals tend to resort to problematic strategies, make less use of problemfocused strategies, and make greater use of emotional-focused strategies, in particular, avoidance [25, 27]. However, neuroticism also predicts support seeking, such as extraversion [25]. Extraversion characterizes assertive, affectionate, and sociable subjects, who tend to experience positive emotions. These individuals seem to resort to maladaptive strategies less, tend to use problem-focused strategies and those emotionfocused strategies that are considered to be positive, such as support, positive thinking, substitution, and more frequently $[25,27,28]$. Openness tends to be creative, original, and psychologically minded [18]. Some evidence suggests the adaptive use of coping strategies in these subjects and, in particular, the use of humor to counter distress [18]; however, the data in the literature appear to be scarce and inconsistent $[27,28]$. Similar results for agreeableness and conscientiousness. Agreeableness indicates people who tend to maintain good relations with others, and it is considered to be an opposite characteristic to the competition. Conscientiousness, instead, tends to describe organized, purposeful, 
reliable, and hardworking people. Compared to other personality traits, agreeableness and conscientiousness seem less investigated with regard to their relationship with coping strategies. However, it seems that people with agreeableness and conscientiousness characteristics make greater use of problem-oriented adaptive strategies than those with lower levels of these personality traits $[18,25,27]$. In summary, it seems that personality traits are, therefore, related to the coping strategies chosen by the subjects. Very interestingly, it seems that personality more strongly predicts coping strategies in stressed samples [25]. This seems important because it encourages us to examine the correlation between personality traits and coping strategies in the evolutionary context of the relationship with S-IDs, which is often a source of stress and a possible negative influence on the child's development. However, if more adaptive personality traits predict more functional coping strategies, and if coping strategies correlate with the quality of the relationship with S-TDs and S-IDs, there is a possible moderating role of the quality of the relationship with brothers and sisters in the relationship between personality traits and coping strategies. As mentioned above, growing up with an S-ID can have an effect on the psychological growth of individuals and could exacerbate certain personality traits. Recent research [4] has shown that adults who have grown up with an S-ID tend to have higher levels of $(\mathrm{N})$ and $(\mathrm{O})$ and lower levels of (E), and these traits may pose a risk of distress and a reduction in the psychological wellbeing of adult S-TDs. Some evidence, derived from typical development dyads, supports an association between personality traits and the quality of the relationship with their brothers or sisters and TD in adulthood. In particular, relationships based on conflict and rivalry seem to be associated with low levels of agreeableness, and, in women, they are associated with high levels of neuroticism and extraversion. Relationships based on warmth, on the other hand, seem to be associated with personality traits such as extraversion and openness. However, we are not aware of any studies that have investigated the association between personality traits and the quality of the reality with siblings in the context of a relationship with S-IDs.

\subsection{Current Study}

The aim of this work is to investigate the predictive value of personality traits in relation to coping strategies and the moderating role of the quality of the relationship between siblings in the relationship between the two previous constructs, comparing individuals with S-TDs and S-IDs. Our model has been based on both previous empirical results and theoretical considerations. The major hypotheses were the following:

Hypothesis 1: Sibling relations will be a significant moderator of the relation between personality traits and stress coping strategies.

Hypothesis 2: Having siblings with or without disabilities (S-IDs vs. S-TDs) is an important factor affecting the interactive effect of sibling relations on the relationship between personality dimensions and styles of coping with stress.

\section{METHODS}

\subsection{Participants}

The participants were 187 adults, of whom 97(51.9\%) were Individuals with brothers or sisters with intellectual disabilities (S-IDs), aged 18 to 60 years $(\mathrm{M}=30.22 ; \mathrm{SD}=12.17)$.

In this group, there were $45(46.39 \%)$ Male and 52(53.61\%) Female. The participants of this group were recruited through community and residential care home settings for intellectual disabilities with the mediation of educators and family doctors, who delivered the collected questionnaires anonymously.

The second group was 90(48.1\%) Individuals with typical developmental siblings (S-TDs) Aged 18 to 76 years $(\mathrm{M}=28.56 ; \mathrm{SD}=11.66)$. In this group, there was 38 Male $(42.2 \%)$ and 52 Female (57.8\%). The participants of this group were recruited through the sports community and also collected questionnaires anonymously.

The participants were presented with written consent request forms describing the nature and aims of the study in compliance with the ethical code of the Italian Association for Psychology. The study was approved by the IRB of the University of Turin (protocol no. 47504). The forms stated that data confidentiality would be assured and that participation in the study was voluntary. All study participants were Italian.

The University of Turin IRB approved the study (Protocol no. 47504). All participants were contacted through associations that deal with intellectual disability and that showed interest in our study. Informed consent was obtained from all individual participants included in the study.

\subsection{Instruments}

The Big Five Questionnaire 2 (BFQ-2) [29]. This is a revised example of the Italian version of the Big Five Questionnaire [30]. This is a self-reported questionnaire composed of 132 items that assess 5 personality dimensions. Subjects indicated agreement with each item based on a 5-point Likert scale, ranging from complete disagreement $(1=$ very false for me) to complete agreement ( $5=$ very true for me). Scales presented a good reliability, as tested using both Cronbach's alpha and McDonald's omega ranging from: $\alpha=$ $.75 ; \omega=.81$ to $\alpha=.86 ; \omega=.86$.

The Coping Orientation to Problem Experiences [19]. Coping strategies were assessed with this self-report questionnaire. For this study, we only used some of the subscales that reflect specific coping strategies: social support, avoidance strategies, positive attitude, and problem-oriented and transcendent-oriented coping strategies. Scales presented a good reliability, ranging from Cronbach's alpha $\alpha=.78$ to $=$ .84 .

The Adult Sibling Relationships Questionnaire (ASRQ) Italian version [31, 32] An Italian version of the ASRQ (Tani \& Ingoglia, 2013) was used to assess the quality of sibling relationships. The ASRQ measures individuals' current perception of their own behavior and feelings toward their siblings, as well as their perception of the sibling's behaviors and feelings toward them. This self-report questionnaire 
comprises 81 items that evaluate three macro-dimensions: warmth, conflict, and rivalry. Subjects rated each item by a five-point Likert scale, ranging from "hardly at all" (1) to "extremely" (5). Warmth scale reliability was $=.79$; conflict scale reliability was: $\alpha=.82$ and rivalry scale was, $\alpha=.74$.

\subsection{Data Analysis}

Data analyses were performed using SPSS 25.0 with the PROCESS macro by A.F. Hayes. Descriptive statistics (M, SD, Skewness, and kurtosis) were examined for all study variables. Bivariate correlations were computed between predictors, covariates, and mediating variables to test for multicollinearity. Bivariate correlations between the control variables (personality and adult sibling relationship) and the outcome (stress coping strategy) were considered in order to select the ones to include in the tested models.

We employed the stepwise regression technique in order to study the direct effects of personality on stress coping strategy in the S-ID and S-TD groups to select dimensions for the moderation model. Next, a moderation model was run to determine whether the relation between the personality traits and stress coping strategy was moderated by the adult sibling relationship for the S-ID or S-TD group. The tested theoretical model is showed in Fig. (1). Moderations analysis was examined using the personality dimension that was significant for both groups (S-IDs and S-TDs), and the moderating effect of sibling relationships was checked. Effect estimates and their 95\% confidence intervals were computed using 10000 random bootstrap samples using the PROCESS macro by A.F. Hayes.

The influences of age and gender were controlled in all of the analyses because the way that gender influences sibling relations was not the aim of this article.

\section{RESULTS}

As the first step in the analyses, we verified the normality of the distribution of the BPQ, ASRQ, STAI, and COPE variables by looking at their skewness and kurtosis values. Descriptive statistics for the study variables and for the differences between the groups are reported in Table $\mathbf{1}$.

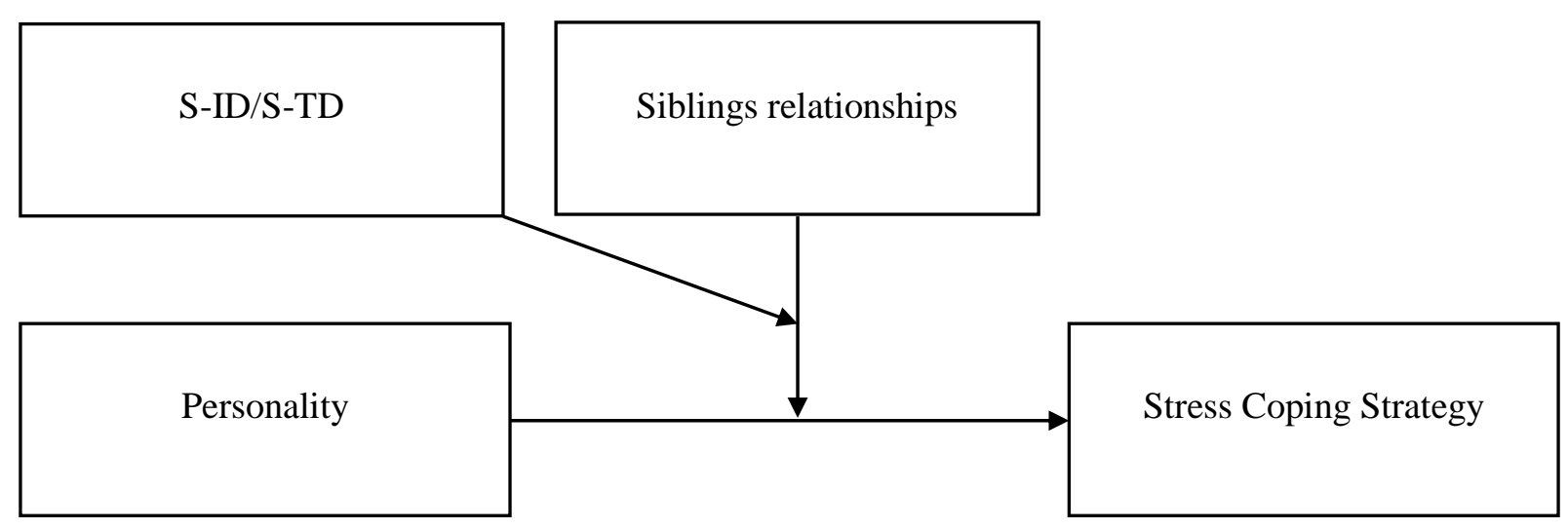

Fig. (1). Theoretical model.

Table 1. Descriptive statistics.

\begin{tabular}{|c|c|c|c|c|c|c|c|c|}
\hline- & \multicolumn{4}{|c|}{ S-ID } & \multicolumn{3}{|c|}{ S-TD } & \\
\hline- & Male & & Female & & Male & & Female & \\
\hline center & $\mathrm{M}$ & SD & $\mathrm{M}$ & SD & $\mathrm{M}$ & SD & $\mathrm{M}$ & SD \\
\hline Age & 30.80 & 14.27 & 29.71 & 10.13 & 30.71 & 11.97 & 26.98 & 11.29 \\
\hline ASRQ & - & - & - & - & - & - & - & - \\
\hline Warmth & 2.94 & 0.71 & 3.07 & 0.79 & 3.05 & 0.62 & 3.17 & 0.79 \\
\hline Conflict & 2.14 & 0.62 & 2.14 & 0.65 & 2.17 & 0.57 & 2.20 & 0.54 \\
\hline Rivalry & 1.98 & 0.93 & 2.12 & 0.89 & 2.05 & 1.03 & 2.16 & 1.02 \\
\hline BFQ & \multicolumn{2}{|l|}{-} & - & \multicolumn{2}{|r|}{-} & \multicolumn{3}{|c|}{-} \\
\hline Dynamism & 40.84 & 7.93 & 43.08 & 7.10 & 43.59 & 7.13 & 43.20 & 6.68 \\
\hline Dominance & 35.57 & 6.02 & 33.20 & 6.82 & 33.73 & 8.06 & 33.16 & 7.03 \\
\hline Extraversion & 76.38 & 12.47 & 76.63 & 11.42 & 78.88 & 11.89 & 76.35 & 11.76 \\
\hline Cooperativity & $44.59^{1 ; 2}$ & 7.56 & $47.88^{1}$ & 7.25 & $48.13^{2}$ & 6.30 & 48.88 & 4.95 \\
\hline Cordiality & $45.05^{2}$ & 6.85 & 46.36 & 7.31 & $48.79^{2}$ & 6.04 & 47.16 & 6.44 \\
\hline Amicability & $89.56^{2}$ & 13.94 & 93.88 & 13.69 & $96.92^{2}$ & 11.33 & 95.86 & 10.07 \\
\hline Scrupolosity & 39.36 & 6.41 & 39.52 & 6.64 & 40.75 & 6.58 & 41.21 & 7.14 \\
\hline Perseverence & $43.62^{2}$ & 6.76 & 43.54 & 7.53 & $46.89^{2}$ & 5.54 & 45.82 & 7.16 \\
\hline
\end{tabular}


(Table 1) contd.....

\begin{tabular}{|c|c|c|c|c|c|c|c|c|}
\hline- & \multicolumn{3}{|c|}{ S-ID } & \multicolumn{4}{|c|}{ S-TD } & \\
\hline Conscientiousness & 82.98 & 11.12 & 82.81 & 12.17 & 87.42 & 8.62 & 87.10 & 11.28 \\
\hline Emotional Control & $37.32^{1}$ & 7.51 & $31.81^{1}$ & 9.07 & $35.76^{1}$ & 7.82 & $31.65^{1}$ & 8.83 \\
\hline Impulse Control & 37.76 & 8.88 & 37.22 & 7.20 & 38.13 & 8.75 & 35.47 & 8.68 \\
\hline Emotional Stability & $75.18^{1}$ & 15.27 & $68.96^{1}$ & 14.26 & 73.89 & 14.98 & 67.14 & 16.45 \\
\hline Openness to culture & 40.04 & 8.27 & 40.63 & 7.43 & 41.54 & 8.38 & 41.27 & 8.04 \\
\hline Openness to experience & 41.80 & 8.20 & 42.75 & 7.44 & 42.83 & 7.88 & 45.18 & 6.00 \\
\hline Openness & 81.84 & 13.88 & 83.42 & 11.92 & 84.31 & 13.49 & 86.58 & 12.55 \\
\hline Egoistic & $21.58^{1}$ & 4.27 & $19.83^{1}$ & 4.21 & 20.13 & 4.92 & 19.67 & 4.46 \\
\hline Moralistic & $17.95^{1}$ & 4.53 & $19.73^{1 ; 3}$ & 3.80 & 18.86 & 4.49 & $18.02^{3}$ & 4.07 \\
\hline COPE & - & - & - & - & - & - & - & - \\
\hline Social support & 29.47 & 6.25 & 31.60 & 7.94 & 31.00 & 8.04 & 33.14 & 7.91 \\
\hline Avoidance strategy & 25.70 & 7.63 & 25.43 & 5.54 & 23.64 & 5.64 & 24.00 & 4.51 \\
\hline Positive attitude & 32.00 & 5.48 & 32.20 & 5.99 & 33.00 & 5.04 & 32.00 & 5.21 \\
\hline Problem-oriented & 33.44 & 5.99 & 31.04 & 5.80 & 33.68 & 4.61 & 31.35 & 6.79 \\
\hline Transcendent-oriented & 15.47 & 5.19 & $16.46^{3}$ & 5.38 & $16.97^{1}$ & 6.11 & $14.10^{1 ; 3}$ & 4.47 \\
\hline
\end{tabular}

S-ID - siblings of people with Intellectual disability S-TD - siblings of people with typical development.

1. Significant differences between men and women in the same group.

2 Significant differences between men in 1 group and men in 2 group.

3 Significant differences between women in 1 group and women in 2 group.

In Table $\mathbf{2}$ and $\mathbf{3}$, we reported the correlations among the study variables. As expected, significant correlations were found between the following: 1. BPQ subscale and COPE scores for both groups, and moreover, for the S-ID group, generally, there were more significant relations between personality and stress coping strategies; 2. BPQ subscale and ASRQ scores for both groups, but again, for the S-IDs, there were more significant relations with amicability and openness; and 3. ASRQ subscale and COPE scores, but only for the S-ID group.

\section{Table 2. Correlation matrix for S-ID group.}

\begin{tabular}{|c|c|c|c|c|c|c|c|c|c|c|c|c|c|c|}
\hline & Variable & 2 & 3 & 4 & 5 & 6 & 7 & 8 & 9 & 10 & 11 & 12 & 13 & 14 \\
\hline 1 & Age & $-.261^{*}$ & $-.476^{* *}$ & $-.369^{* *}$ & .062 & -.130 & -.112 & -.103 & .145 & -.024 & .205 & -.011 & -.014 & $.225^{*}$ \\
\hline 2 & BFQ - Extraversion & 1 & $.289^{* *}$ & $.384^{* *}$ & .036 & $.409^{* *}$ & .023 & .024 & -.030 & -.064 & $-.233^{*}$ & .070 & $.225^{*}$ & -.186 \\
\hline 3 & BFQ - Amicability & - & 1 & $.570^{* *}$ & .132 & $.652^{* *}$ & $.311^{* *}$ & -.187 & $-.222^{*}$ & $.220^{*}$ & $-.493^{* *}$ & $.373^{* *}$ & .172 & -.173 \\
\hline 4 & BFQ - Conscientiousness & - & - & 1 & .154 & $.447^{* *}$ & .123 & -.057 & -.054 & .029 & $-.429^{* *}$ & $.210^{*}$ & $.300^{* *}$ & $-.212^{*}$ \\
\hline 5 & BFQ - Emotional Stability & - & - & - & 1 & .125 & .115 & -.133 & -.050 & $-.278^{* *}$ & $-.279^{* *}$ & .194 & .071 & .103 \\
\hline 6 & BFQ - Openness & - & - & - & - & 1 & .109 & $-.233^{*}$ & -.206 & -.003 & $-.398^{* *}$ & $.236^{*}$ & $.246^{*}$ & -.203 \\
\hline 7 & ASRQ - Warmth & - & - & - & - & - & 1 & .095 & -.063 & -.026 & $-.344^{* *}$ & .059 & -.150 & .067 \\
\hline 8 & ASRQ - Conflict & - & - & - & - & - & - & 1 & $.412^{* *}$ & -.116 & .201 & -.010 & -.051 & .191 \\
\hline 9 & ASRQ - Rivalry & - & - & - & - & - & - & - & 1 & -.002 & $.288^{* *}$ & -.150 & -.170 & .023 \\
\hline 10 & COPE - Social support & - & - & - & - & - & - & - & - & 1 & .178 & $.208^{*}$ & $.448^{* *}$ & .134 \\
\hline 11 & COPE - Avoidance strategy & - & - & - & - & - & - & - & - & - & 1 & .003 & .042 & $.384^{* *}$ \\
\hline 12 & COPE - Positive attitude & - & - & - & - & - & - & - & - & - & - & 1 & $.548^{* *} .394^{* *}$ \\
\hline 13 & COPE - Problem-oriented & - & - & - & - & - & - & - & - & - & - & - & 1 & .173 \\
\hline 14 & COPE - Transcendent-oriented & - & - & - & - & - & - & - & - & - & - & - & - & 1 \\
\hline
\end{tabular}

Note: BFQ II - Big Five Questionnaire (G.V.Caprara.C.Barbaranelli.L.Borgogni.M.Vecchione 2007) ASRQ -Adult Sibling Relationship Questionnaire (C. Stocker. R.

Lanthier. W. Furman 1997) COPE - Coping Orientations to Problem Experienced (Carver. Scheier. Weintraub. 1989).

$*-\mathrm{p}<.05 * *-\mathrm{p}<.01$

Table 3. Correlation matrix for S-TD group.

\begin{tabular}{|c|c|c|c|c|c|c|c|c|c|c|c|c|c|c|}
\hline & Variable & 2 & 3 & 4 & 5 & 6 & 7 & 8 & 9 & 10 & 11 & 12 & 13 & 14 \\
\hline 1 & Age & $.282^{* *}$ & -.106 & .191 & -.076 & -.001 & -.046 & -.206 & .025 & .062 & .204 & .171 & $.218^{*}$ & $.391^{* *}$ \\
\hline 2 & BFQ - Extraversion & 1 & $.420^{* *}$ & $.260^{*}$ & .116 & $.403^{* *}$ & .152 & -.020 & .019 & $.296^{* *}$ & -.093 & .191 & $.479^{* *}$ & .188 \\
\hline 3 & BFQ - Amicability & - & 1 & .126 & $.335^{* *}$ & $.464^{* *}$ & .149 & .086 & .137 & $.309^{* *}$ & $-.226^{*}$ & $.235^{*}$ & .176 & -.003 \\
\hline 4 & BFQ - Conscientiousness & - & - & 1 & -.116 & $.339^{* *}$ & .067 & -.218 & $-.296^{* *}$ & .085 & -.143 & .019 & $.395^{* *}$ & -.057 \\
\hline 5 & BFQ - Emotional Stability & - & - & - & 1 & $.355^{* *}$ & -.058 & -.019 & -.006 & $-.333^{* *}$ & $-.417^{* *}$ & .187 & .064 & -.092 \\
\hline 6 & BFQ - Openness & - & - & - & - & 1 & .007 & -.063 & -.015 & .070 & $-.334^{* *}$ & .135 & $.363^{* *}$ & -.155 \\
\hline
\end{tabular}


(Table 3) contd.....

\begin{tabular}{|c|c|c|c|c|c|c|c|c|c|c|c|c|c|c|}
\hline 7 & ASRQ - Warmth & - & - & - & - & - & 1 & .087 & -.164 & .092 & .156 & .011 & .019 & .190 \\
\hline 8 & ASRQ - Conflict & - & - & - & - & - & - & 1 & $.325 * *$ & -.074 & .145 & -.036 & -.102 & -.092 \\
\hline 9 & ASRQ - Rivalry & - & - & - & - & - & - & - & 1 & .103 & .063 & .201 & -.040 & .062 \\
\hline 10 & COPE - Social support & - & - & - & - & - & - & - & - & 1 & .116 & .177 & $.312 * *$ & .002 \\
\hline 11 & COPE - Avoidance strategy & - & - & - & - & - & - & - & - & - & 1 & $.251 *$ & .100 & $.492 * *$ \\
\hline 12 & COPE - Positive attitude & - & - & - & - & - & - & - & - & - & - & 1 & $.514 * *$ & $.362 * *$ \\
\hline 13 & COPE - Problem-oriented & - & - & - & - & - & - & - & - & - & - & - & 1 & $.270 *$ \\
\hline 14 & COPE - Transcendent-oriented & - & - & - & - & - & - & - & - & - & - & - & - & 1 \\
\hline
\end{tabular}

Note: BFQ II - Big Five Questionnaire(G.V.Caprara.C.Barbaranelli.L.Borgogni.M.Vecchione 2007) ASRQ -Adult Sibling Relationship Questionnaire (C. Stocker. R. Lanthier. W. Furman 1997) COPE - Coping Orientations to Problem Experienced (Carver. Scheier. Weintraub. 1989)

$*-\mathrm{p}<.05^{* *}-\mathrm{p}<.01$

Focusing on the differences in correlation between the SID and STD groups, it can be seen that there is a very interesting age result. In the SID group, age negatively correlates with extraversion, while in the STD group, age correlates positively with extraversion. Another difference worth noting is in the relationship between personality dimensions and coping strategies. In the SID group, there is a negative relationship between extraversion and avoidance strategy and conscientiousness and transcendent-oriented strategy, which does not exist for the STD group.

The last element that differentiates the correlation tables for the SID and STD groups is the relationship between sibling relations and stress coping strategies, which is significant for the SID group in the case of the warmth and rivalry scales and which correlates negatively with the avoidance strategy dimension. In the case of the STD group, no relationship between sibling relations and stress coping strategy was demonstrated.

Next, stepwise regression models were run to examine which personality traits most influence the stress coping strategies in the S-TD and S-ID groups.

The results of the regression model for social support showed that, for the S-ID group, there were three significant dimensions $\left(\mathrm{F}(3.78)=7.336 ; \mathrm{p}<0.001 ; \mathrm{R}^{2}=22 \%\right)$ : emotional stability $(\beta=-0.38 . \mathrm{p}<0.001)$; amicability $(\beta=0.41 . \mathrm{p}<$ $0.001)$; and openness $(\beta=-0.27 . p<0.05)$. In this case, for the
S-TD group, there are only two significant predictors $(\mathrm{F}(2.71)$ $\left.=18.492 ; \mathrm{p}<0.001 ; \mathrm{R}^{2}=34 \%\right)$ : emotional stability $(\beta=-0.43$. $\mathrm{p}<0.001)$ and amicability $(\beta=0.54 . \mathrm{p}<0.001)$.

Next, in the same way, an analysis was carried out for the avoidance strategy. It turned out that for the S-IDs, there were two significant predictors $\left(\mathrm{F}(2.77)=14.951 ; \mathrm{p}<0.001 ; \mathrm{R}^{2}=\right.$ $28 \%)$ : emotional stability $(\beta=-0.21 . \mathrm{p}<0.05)$ and amicability $(\beta=-0.45 . \mathrm{p}<0.001)$.

For the S-TDs, there were also two significant predictors $\left(\mathrm{F}(2.70)=10.541 ; \mathrm{p}<0.001 ; \mathrm{R}^{2}=23.1 \%\right)$, but it was emotional stability $(\beta=-0.53 . \mathrm{p}<0.001)$ and Lie $(\beta=0.27 . \mathrm{p}<$ $0.05)$.

The results of the regression model for a positive attitude showed one predictor that was significant for the S-ID group $\left(\mathrm{F}(1.78)=10.541 ; \mathrm{p}<0.01 ; \mathrm{R}^{2}=10.8 \%\right)$ : amicability $(\beta=$ $0.35 . \mathrm{p}<0.001)$ But, for the S-TDs, there were two significant predictors $\left(\mathrm{F}(2.72)=5.724 ; \mathrm{p}<0.001 ; \mathrm{R}^{2}=11.3\right)$ : amicability $(\beta=0.23 . p<0.05)$ and Lie $(\beta=0.26 . p<0.05)$

The results of the regression model for problem-oriented showed one predictor that was significant for the S-ID group $\left(\mathrm{F}(1.79)=5.649 ; \mathrm{p}<0.05 ; \mathrm{R}^{2}=5.5 \%\right)$ : extraversion $(\beta=0.26$. $\mathrm{p}<0.05)$. But, for the S-TDs, there were two significant predictors $\left(\mathrm{F}(2.72)=19.835 ; \mathrm{p}<0.001 ; \mathrm{R}^{2}=33.7 \%\right)$ : extraversion $(\beta=0.41 . p<0.001)$ and conscientiousness $(\beta=$ 0.33. $\mathrm{p}<0.05)$ (Table 4).

Table 4. Stepwise regression models with personality traits as a predictor and stress coping strategies as a dependent variable in the S-ID and S-TD groups. In the table, there are presented the best-fitted models.

\begin{tabular}{|c|c|c|c|c|c|c|c|c|c|c|c|c|}
\hline - & - & - & \multicolumn{5}{|c|}{ S-ID } & \multicolumn{5}{|c|}{ S-TD } \\
\hline - & Predictor & - & $\mathbf{R}^{2}$ & $\operatorname{Adj-R}{ }^{2}$ & $\beta$ & $t$ & $p$ & $\mathbf{R}^{2}$ & ${\operatorname{Adj}-R^{2}}^{2}$ & $\beta$ & $t$ & $p$ \\
\hline 1 & \multicolumn{7}{|c|}{ dependent variable: social support } & - & - & - & - & - \\
\hline - & - & - & .22 & 19 & - & - & - & .34 & .32 & - & - & - \\
\hline - & constant & - & - & - & - & .175 & .862 & - & - & - & .65 & .949 \\
\hline- & \multicolumn{3}{|c|}{ Emotional Stability } & - & -.38 & 3.737 & $<0.001$ & - & - & -.43 & 4.291 & $<0.001$ \\
\hline - & \multicolumn{2}{|l|}{ Amicability } & - & - & .41 & 3.089 & $<0.001$ & - & - & .54 & 5.358 & $<0.001$ \\
\hline- & \multicolumn{2}{|l|}{ Openness } & - & - & -.27 & 2.025 & $<0.05$ & - & - & - & - & - \\
\hline 2 & \multicolumn{7}{|c|}{ dependent variable: avoidance strategy } & - & - & - & - & - \\
\hline- & - & - & .28 & .26 & - & - & - & .23 & .21 & - & - & - \\
\hline- & constant & - & - & - & - & .510 & .611 & - & - & - & 2.326 & $<0.05$ \\
\hline - & \multicolumn{3}{|c|}{ Emotional Stability } & - & -.21 & 2.162 & $<0.05$ & - & - & -.53 & 4.578 & $<0.001$ \\
\hline - & \multicolumn{2}{|l|}{ Amicability } & - & - & -.45 & 4.616 & $<0.001$ & - & - & - & - & - \\
\hline- & Lie & - & - & - & - & - & - & - & - & .27 & 2.311 & $<0.05$ \\
\hline 3 & \multicolumn{7}{|c|}{ dependent variable: positive attitude } & - & - & - & - & - \\
\hline
\end{tabular}


(Table 4) contd.....

\begin{tabular}{|c|c|c|c|c|c|c|c|c|c|c|c|c|}
\hline \multirow[t]{2}{*}{-} & \multirow{2}{*}{$\frac{-}{\text { Predictor }}$} & \multirow[t]{2}{*}{ - } & \multicolumn{5}{|c|}{ S-ID } & \multicolumn{5}{|c|}{ S-TD } \\
\hline & & & $\mathbf{R}^{2}$ & Adj-R ${ }^{2}$ & $\beta$ & $t$ & $p$ & $\mathbf{R}^{2}$ & Adj-R ${ }^{2}$ & $\beta$ & $t$ & $p$ \\
\hline - & - & - & .12 & .11 & - & - & - & .14 & .11 & - & - & - \\
\hline- & constant & - & - & - & - & .669 & .506 & - & - & - & .127 & .889 \\
\hline- & \multicolumn{2}{|c|}{ Amicability } & - & - & .35 & 3.247 & $<0.001$ & - & - & .23 & 2.028 & $<0.05$ \\
\hline- & Lie & - & - & - & - & - & - & - & - & .26 & 2.29 & $<0.05$ \\
\hline 4 & \multicolumn{7}{|c|}{ dependent variable: problem-oriented } & - & - & - & - & - \\
\hline- & - & - & .06 & .05 & - & - & - & .36 & .34 & - & - & - \\
\hline- & constant & - & - & - & - & .744 & .459 & - & - & - & .602 & .549 \\
\hline- & \multicolumn{2}{|c|}{ Extraversion } & - & - & .26 & 2.377 & $<0.05$ & - & - & .41 & 4.15 & $<0.001$ \\
\hline- & \multicolumn{3}{|c|}{ Conscientiousness } & - & - & - & - & - & - & .33 & 3.317 & $<0.001$ \\
\hline
\end{tabular}

Finally, using PROCESS by A.F. Hayes, we carried out an analysis between personality and the stress-coping strategy with adult sibling relationships as a moderator, and this was performed for both groups (S-IDs/S-TDs) separately.

For this model, we chose the personality traits that were significant predictors for both groups from the stepwise regression model that was performed earlier on.

The first moderation analysis was performed for the relationship between emotional stability and social support
(Figs. 2a and 3a). It is worth noting that there are significant moderation effects for each dimension of adult sibling relationships for both groups and at the figures, we demonstrated only significant relations, which are different between the groups. However, there are differences between the relationships in each group. For the warmth scale, a significant moderation effect for low warmth levels was demonstrated in the S-ID group (Table 5; Fig. 3a), while for the S-TD group, a significant moderation effect for high warmth levels was shown (Table 6; Fig. 2a).

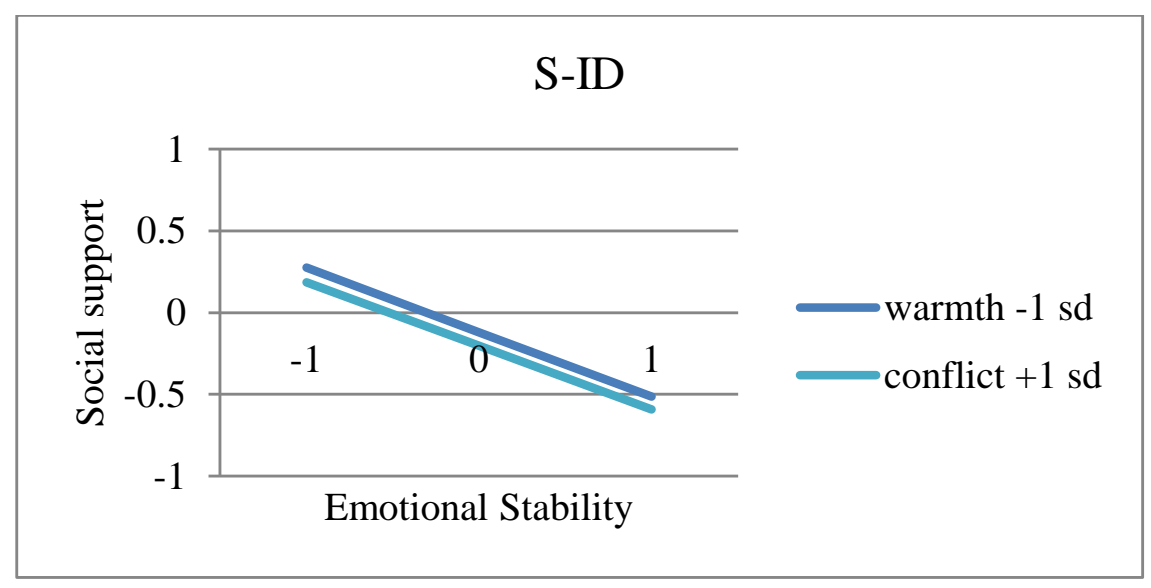

$2 \mathrm{a}$

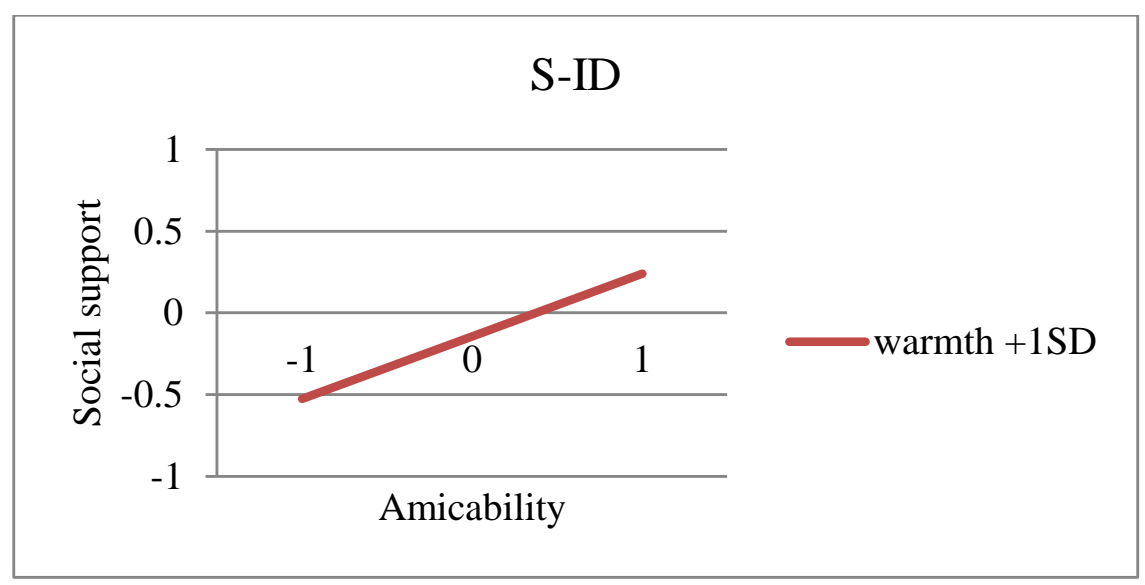




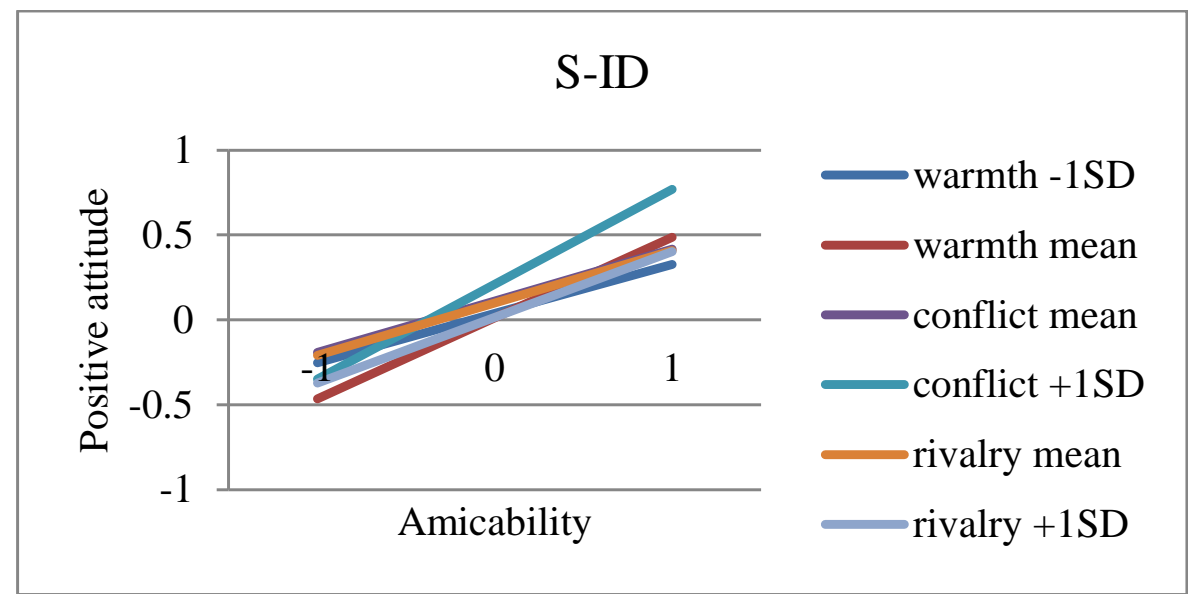

2c

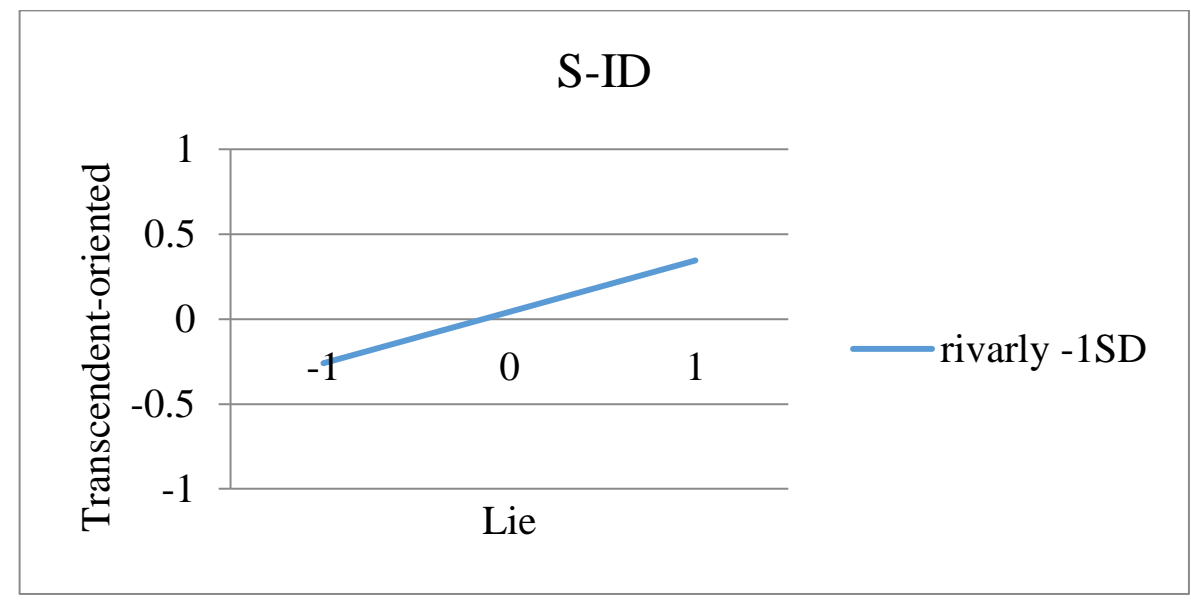

$2 d$

Fig. (2). Graphical illustration of the significant effects for S-ID, but only those which are different from the S-TD group..

Table 5. Conditional effect of personality (BPQ-2) on stress coping strategies (COPE) at values of Adult siblings relationship for S-ID (Different significant effects than in S-TD group are marked in bold).

\begin{tabular}{|c|c|c|c|c|c|c|c|c|c|c|c|c|}
\hline & \multicolumn{2}{|c|}{$\begin{array}{l}\text { Emotional Stability } \\
\text { Social support }\end{array}$} & \multicolumn{2}{|c|}{$\begin{array}{c}\text { Amicability } \\
\text { Social support }\end{array}$} & \multicolumn{2}{|c|}{$\begin{array}{l}\text { Emotional Stability } \\
\text { Avoidance strategy }\end{array}$} & \multicolumn{2}{|c|}{$\begin{array}{c}\text { Amicability } \\
\text { Positive attitude }\end{array}$} & \multicolumn{2}{|c|}{$\begin{array}{c}\text { Extraversion } \\
\text { Problem-oriented }\end{array}$} & \multicolumn{2}{|c|}{\begin{tabular}{|c|} 
Lie \\
Transcendent-oriented
\end{tabular}} \\
\hline & $\begin{array}{c}\text { Standardized } \\
\text { Estimate }\end{array}$ & $p$ & $\begin{array}{c}\text { Standardized } \\
\text { Estimate }\end{array}$ & $P$ & $\begin{array}{c}\text { Standardized } \\
\text { Estimate }\end{array}$ & $p$ & $\begin{array}{c}\text { Standardized } \\
\text { Estimate }\end{array}$ & $p$ & \begin{tabular}{|c} 
Standardized \\
Estimate
\end{tabular} & $p$ & $\begin{array}{l}\text { Standardized } \\
\text { Estimate }\end{array}$ & $p$ \\
\hline $\begin{array}{l}\text { warmth } \\
-1 \mathrm{SD}\end{array}$ & -.414 & $.0116^{*}$ & .1562 & .1897 & $-0,2075$ & .1964 & .2729 & $.018^{*}$ & 2951 & .0506 & .2804 & .0845 \\
\hline $\begin{array}{l}\text { warmth } \\
\text { mean }\end{array}$ & -.2436 & $.0392 *$ & .2587 & $.0122 *$ & -.2586 & $.0267^{*}$ & .4488 & $\mid<0,001 * *$ & .285 & $.0109 *$ & .245 & .0568 \\
\hline $\begin{array}{l}\text { warmth } \\
1 \mathrm{SD}\end{array}$ & -.0732 & .6467 & .3612 & $.0389 *$ & -.3097 & .0503 & 6248 & $.0003 * *$ & . 2749 & .1204 & 2097 & 2657 \\
\hline $\begin{array}{l}\text { conflict } \\
-1 \mathrm{SD}\end{array}$ & -.4094 & $.0051 * *$ & .1569 & .3015 & -.3142 & $.0364 *$ & .0481 & .7405 & .1279 & .3916 & .1365 & .3551 \\
\hline $\begin{array}{l}\text { conflict } \\
\text { mean }\end{array}$ & -.4024 & $.0003 * *$ & .176 & .069 & -.3128 & $.0061 * *$ & .2964 & $.0014 * *$ & .2107 & $.0433 *$ & .1973 & .0954 \\
\hline $\begin{array}{l}\text { conflict } \\
1 \mathrm{SD}\end{array}$ & -.3954 & $.0175 *$ & .1952 & .1271 & -.3114 & .0735 & .5448 & $<0,001 * *$ & .2935 & $.0411 *$ & .2581 & .1215 \\
\hline
\end{tabular}


(Table $\square$ ) contd.....

\begin{tabular}{|c|c|c|c|c|c|c|c|c|c|c|c|c|}
\hline & \multicolumn{2}{|c|}{$\begin{array}{c}\text { Emotional Stability } \\
\text { Social support }\end{array}$} & \multicolumn{2}{|c|}{$\begin{array}{c}\text { Amicability } \\
\text { Social support }\end{array}$} & \multicolumn{2}{|c|}{$\begin{array}{l}\text { Emotional Stability } \\
\text { Avoidance strategy }\end{array}$} & \multicolumn{2}{|c|}{$\begin{array}{c}\text { Amicability } \\
\text { Positive attitude }\end{array}$} & \multicolumn{2}{|c|}{$\begin{array}{c}\text { Extraversion } \\
\text { Problem-oriented }\end{array}$} & \multicolumn{2}{|c|}{\begin{tabular}{|c} 
Lie \\
Transcendent-oriented
\end{tabular}} \\
\hline & $\begin{array}{c}\text { Standardized } \\
\text { Estimate }\end{array}$ & $p$ & $\begin{array}{c}\text { Standardized } \\
\text { Estimate }\end{array}$ & $P$ & $\begin{array}{c}\text { Standardized } \\
\text { Estimate }\end{array}$ & $p$ & $\begin{array}{c}\text { Standardized } \\
\text { Estimate }\end{array}$ & $p$ & $\begin{array}{c}\text { Standardized } \\
\text { Estimate }\end{array}$ & $p$ & $\begin{array}{l}\text { Standardized } \\
\text { Estimate }\end{array}$ & $p$ \\
\hline $\begin{array}{l}\text { rivalry } \\
-1 \mathrm{SD}\end{array}$ & -.4176 & $.0083 * *$ & .050 & .7655 & -.1905 & .2134 & .2258 & .1808 & .3572 & $.021 *$ & .3152 & $.0421^{*}$ \\
\hline $\begin{array}{l}\text { rivalry } \\
\text { mean }\end{array}$ & -.2532 & $.0204 *$ & .2013 & $.0293 *$ & -.2883 & $.0071 * *$ & .3019 & $.0013 * *$ & .2375 & $.0238 *$ & .1482 & .2106 \\
\hline $\begin{array}{l}\text { rivalry } \\
1 \mathrm{SD}\end{array}$ & -.0887 & .5568 & .3527 & $.0153 *$ & -.3861 & $.0095 * *$ & .3781 & $.0098 * *$ & .1178 & .4196 & -.0187 & .9218 \\
\hline
\end{tabular}

Table 6. Conditional effect of personality (BPQ-2) on stress coping strategies (COPE) at values of Adult siblings relationship for S-TD (Different significant effects than in S-ID group are marked in bold).

\begin{tabular}{|c|c|c|c|c|c|c|c|c|c|c|c|c|}
\hline & \multicolumn{2}{|c|}{$\begin{array}{c}\text { Emotional Stability } \\
\text { Social support }\end{array}$} & \multicolumn{2}{|c|}{$\begin{array}{c}\text { Amicability } \\
\text { Social support }\end{array}$} & \multicolumn{2}{|c|}{$\begin{array}{l}\text { Emotional Stability } \\
\text { Avoidance strategy }\end{array}$} & \multicolumn{2}{|c|}{$\begin{array}{c}\text { Amicability } \\
\text { Positive attitude }\end{array}$} & \multicolumn{2}{|c|}{$\begin{array}{c}\text { Extraversion } \\
\text { Problem-oriented }\end{array}$} & \multicolumn{2}{|c|}{\begin{tabular}{|c|} 
Lie \\
Transcendent-oriented
\end{tabular}} \\
\hline & \begin{tabular}{|c|} 
Standardized \\
Estimate
\end{tabular} & $p$ & \begin{tabular}{|c|}
$\begin{array}{c}\text { Standardized } \\
\text { Estimate }\end{array}$ \\
\end{tabular} & $p$ & \begin{tabular}{|c|} 
Standardized \\
Estimate
\end{tabular} & $p$ & \begin{tabular}{|c|} 
Standardized \\
Estimate
\end{tabular} & $p$ & \begin{tabular}{|c|} 
Standardized \\
Estimate
\end{tabular} & $p$ & \begin{tabular}{|c|} 
Standardized \\
Estimate
\end{tabular} & $p$ \\
\hline $\begin{array}{l}\text { warmth } \\
-1 \mathrm{SD}\end{array}$ & -.1707 & .3009 & .3785 & .0319 & -.2352 & .1402 & .1666 & .7193 & .4212 & $.0066^{* *}$ & .0652 & .759 \\
\hline \begin{tabular}{l|} 
warmth \\
mean
\end{tabular} & -.2449 & $.0317 *$ & .3164 & $.0149 *$ & -.3401 & $.0021 *$ & .1232 & .1108 & .5068 & $<0,001 * * *$ & .2646 & $.0386^{*}$ \\
\hline $\begin{array}{l}\text { warmth } \\
1 \mathrm{SD}\end{array}$ & -.319 & $.0365 *$ & .2543 & .2029 & -.445 & $.0032 * *$ & .1913 & $.0186 *$ & .5925 & $.0001 * *$ & .464 & $.0042 * *$ \\
\hline $\begin{array}{l}\text { conflict } \\
-1 \mathrm{SD}\end{array}$ & -.3628 & $.0301 *$ & .2294 & .2345 & -.3746 & $.0288^{*}$ & .1758 & .3308 & .5993 & $.0008^{* *}$ & .2973 & .0811 \\
\hline $\begin{array}{l}\text { conflict } \\
\text { mean }\end{array}$ & -.3125 & $.0034 * *$ & .4471 & $.0007 * *$ & -.3514 & $.0011 * *$ & .2338 & .0577 & .5189 & $<0,001 * * *$ & .2696 & $.0214^{*}$ \\
\hline $\begin{array}{l}\text { conflict } \\
1 \mathrm{SD}\end{array}$ & -.2623 & .0742 & .6649 & $.0035 *$ & -.3282 & $.0224^{*}$ & .2917 & .1782 & .4385 & $.0013^{* *}$ & .2418 & .1707 \\
\hline $\begin{array}{l}\text { rivalry } \\
-1 \mathrm{SD}\end{array}$ & -.3392 & $.0263 *$ & .2554 & .1427 & -.3765 & $.0092 * *$ & -.0066 & .9694 & .4174 & $.0065 * *$ & .0877 & .5866 \\
\hline $\begin{array}{l}\text { rivalry } \\
\text { mean }\end{array}$ & -.2435 & $.0271^{*}$ & .4576 & $.0003 * *$ & -.3353 & $.0016^{* *}$ & .1972 & .1149 & .4906 & $<0,001 * * *$ & .2976 & $.0104 *$ \\
\hline $\begin{array}{l}\text { rivalry } \\
1 \mathrm{SD}\end{array}$ & -.1477 & .3219 & .6598 & $.0001 * *$ & -.2941 & $.0437 *$ & .401 & $.0196 *$ & .5637 & $<0,001 * * *$ & .5075 & $.0013 * *$ \\
\hline
\end{tabular}

Moving to the conflict dimension in the S-ID group for each level of conflict intensity, a significant moderation effect between emotional stability and social support was demonstrated (Table 5; Fig. 2a), and in the S-TD group, the effect was obtained for low and medium levels of conflict (Table 6). In the rivalry dimension, similar results were obtained in both groups, but stronger effects were demonstrated in the S-ID group (Table 5 and $\mathbf{6}$ ).

A second moderation analysis was carried out for the relationship between amicability and social support. In this case, one can also observe differences between dependencies in the groups. For the warmth scale, a significant moderation effect for high warmth levels was demonstrated in the S-ID group (Table 5; Fig. 2b), while for the S-TD group, a significant moderation effect for low warmth levels was shown (Table 6; Fig. 3b). In addition, in the case of the conflict dimension, a significant moderation effect was demonstrated only in the S-TD group for medium and high levels of this dimension (Table 6; Fig. 3b). Analyzing the results for the moderation rivalry effect, a significant result was noted for medium and high rivalry levels in both groups, but the strength of dependence for the S-TD group is much higher (Table 5).
The third moderation analysis was carried out for the relationship between emotional stability and avoidance strategy. Also, in this case, a number of differences in the moderation effect between the groups were demonstrated. In the case of the warmth dimension, a significant moderation effect was demonstrated for both groups, but only for an average warmth level (Table $\mathbf{5}$ and $\mathbf{6}$ ), and in the case of a high warmth level, only the S-TD group showed a significant relationship (Table 6; Fig. 3c). The analysis for the conflict dimension showed a significant effect for low and medium conflict intensity for the S-IDs and a significant effect for the S-TD group for each level of conflict intensity (Table 6; Fig. 3c). The higher the conflict level, the weaker the effect for the S-TD group, and the estimation level for the group remained at a similar level. Referring to the moderation rivalry effect, it turned out that for the S-ID group, an important moderator is medium and high levels of rivalry, but for the S-TD group, the moderation effect occurs for each rivalry level (Table 6; Fig. 3c). It is noteworthy that the level of estimation for the S-ID group increases as the rivalry level increases, while in the case of the S-TDs, it decreases. 


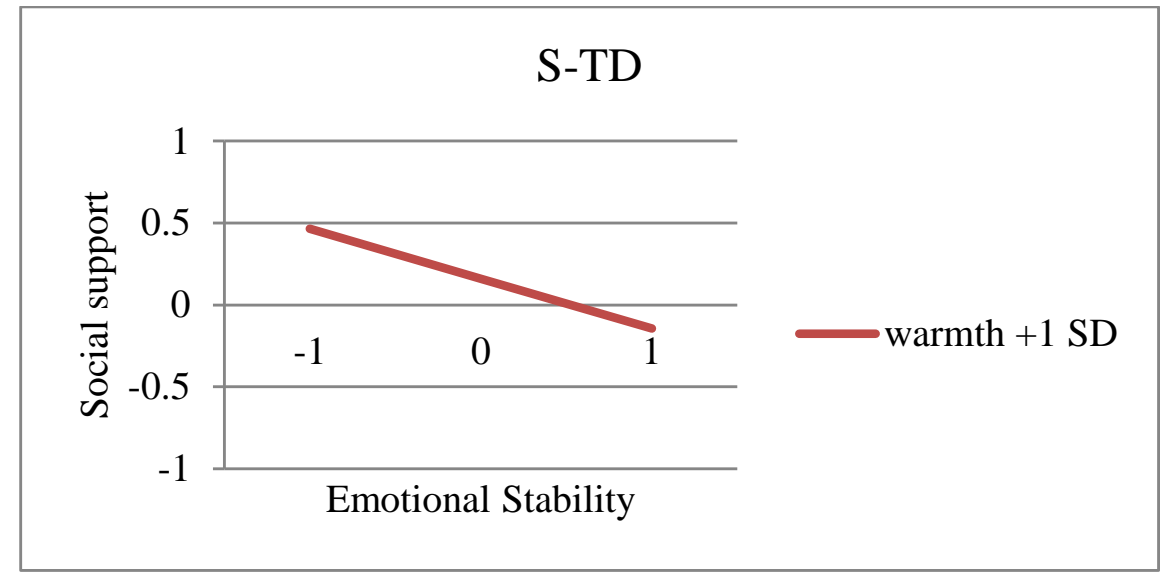

$3 a$

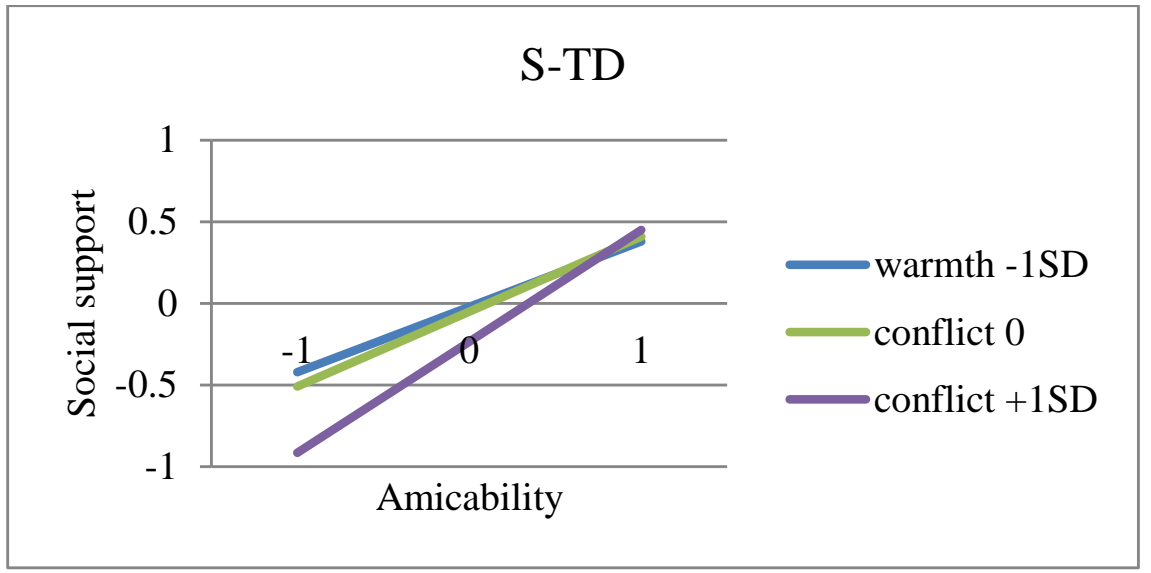

$3 b$

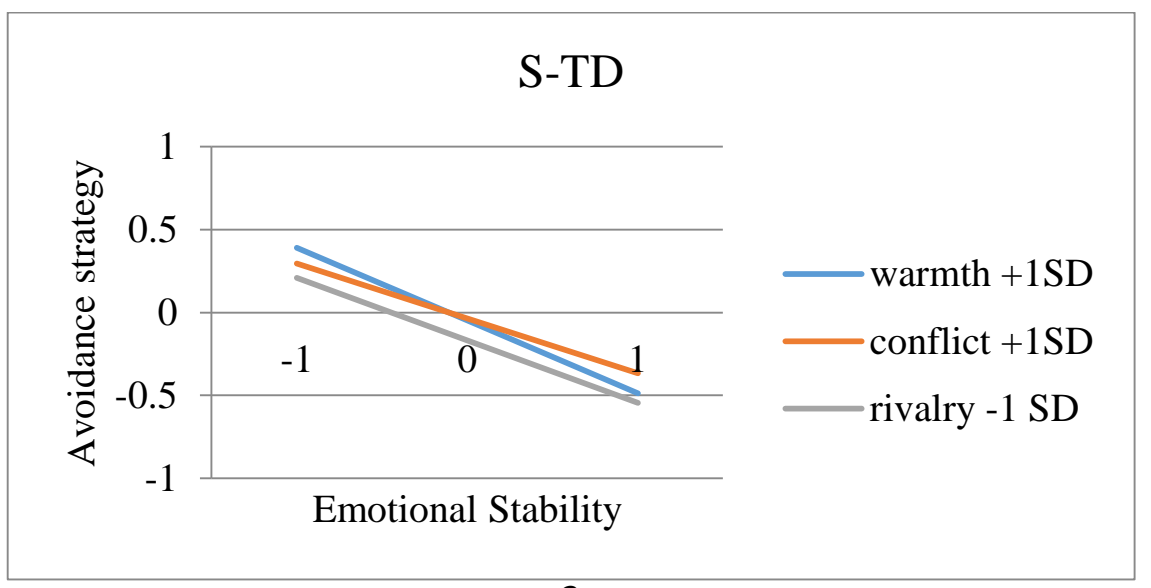

$3 c$

Fig. $\square$ contd..... 


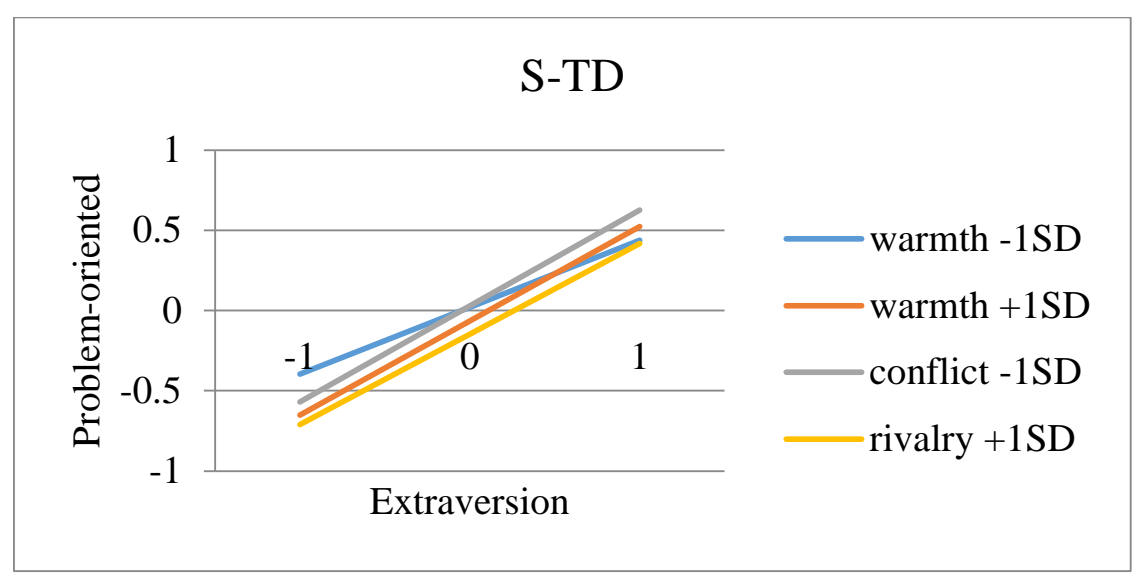

$3 d$

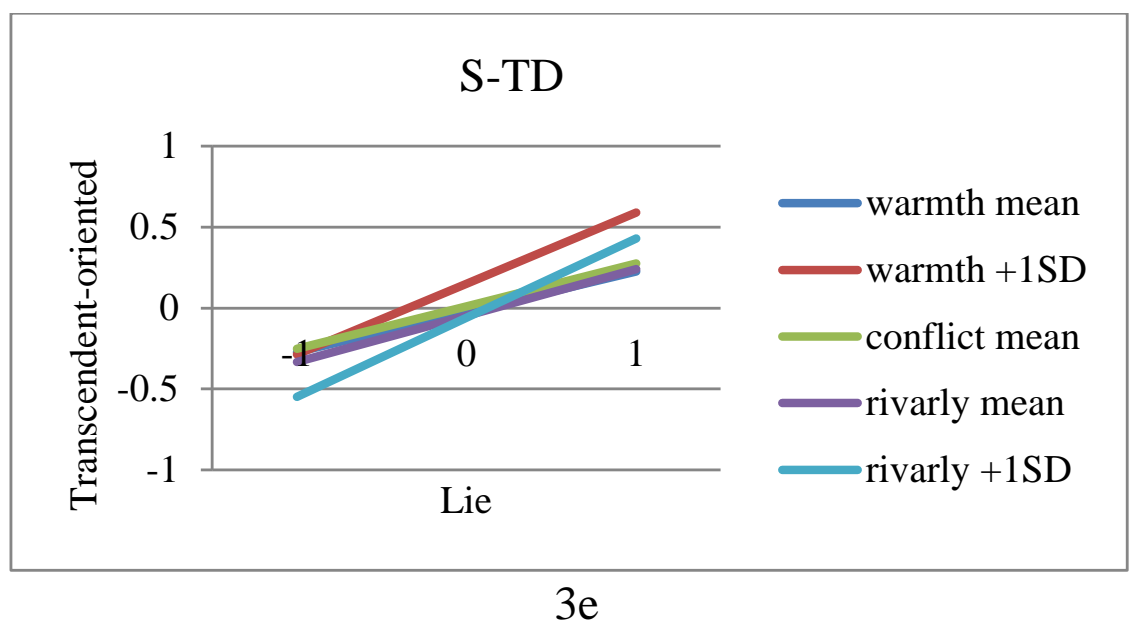

Fig. (3). Graphical illustration of the significant effects for S-TD, but only those which are different from the S-ID group.

The fourth moderation analysis was performed for the relationship between amicability and a positive attitude. Also, in this case, a number of differences in the moderation effect between the groups were demonstrated. Focusing on the warmth moderation effect at the outset, it can be seen that there is a significant effect for the entire spectrum of warmth results for the S-ID group (Table 5; Fig. 2c). It is the strongest for high-intensity warmth in the S-ID group, and in the S-TD group, it is definitely lower and relevant for only a high intensity (Table 6).

Analyzing the moderation function of conflict, depending on the relationship between amicability and a positive attitude, attention is drawn to the occurrence of significant effects for only the S-ID group (Table 5; Fig. 2c) and the increasing estimate with increasing conflict intensity. Moving to the last dimension of sibling relations, which is rivalry, the analyzed results show a significant moderation effect for medium- and high-level rivalry for the S-ID group, as in the case of conflict, (Table 5; Fig. 2c). A significant rivalry moderating effect was demonstrated for the S-TD group (Table 6).
The fifth moderation analysis was performed for the relationship between extraversion and problem-oriented. Also, in this case, a number of differences in the moderation effect between the groups were demonstrated (Table $\mathbf{5}$ and $\mathbf{5}$ ). The first difference between the groups is visible in the case of the moderation warmth effect, which turned out to be significant for the average level of the mentioned dimension in the S-ID group (Table 5) and for each intensity of the discussed dimension in the S-TD group (Table 6; Fig. 3d). The effect strength increases in direct proportion to the warmth increase. Another dimension that is a moderator of the relationship between extraversion and problem-oriented is conflict. The results obtained in the S-ID group are significant for medium and high levels of conflict, and the effect strength is greater with greater dimension intensity. However, in the case of the STD group, a significant effect was obtained for each level of conflict intensity, but the strength of the coefficient decreases as the conflict increases (Table 6; Fig. 3d). In the case of the rivalry dimension, an inverse relationship was noted too that in the conflict case, and, namely, in the S-ID group, the estimated strength is lower as rivalry increases (Table 5). Whereas, in the 
S-TD group, the strength of the coefficients is higher the rivalry level we take into account, and the results are relevant for each moderator level (Table 6; Fig. 3d). The last moderation effect calculated for the rivalry dimension showed the only significant effect for the S-ID group for a low level of rivalry, while for the S-TD group, significant effects for medium and high levels of rivalry were shown, and the level of estimation was higher with higher intensity of the moderator (Table 5 and 6; Fig. 3d).

The sixth moderation analysis was performed for the relationship between the lie and transcendent-oriented. Also, in this case, a number of differences in the effect of moderation between the groups were shown (Table 5 and 6). The differences in the relationships between the groups are already visible in the warmth dimension, which has a moderate function that is only significant in the case of the STD group for medium and high levels of moderators (Table 6; Fig. 3e). For the conflict dimension, the results were similar except that the effect is only relevant for the average level of conflict in the STD group (Table 6; Fig. 3e). The last moderation effect calculated for the rivalry dimension showed the only significant effect for the SID group for a low level of rivalry (Table 5; Fig. 2d), while for the STD group, significant effects for medium and high levels of rivalry were shown, and the level of estimation was higher with the higher intensity of the moderator (Table 6; Fig. 3e).

\section{DISCUSSION}

The aim of this work is to investigate the predictive value of personality traits in relation to coping strategies and the moderating role of the quality of the relationship between siblings in the relationship between the two previous constructs, comparing individuals with brothers or sisters with typical development (S-TDs) and those with siblings with disabilities (S-IDs).

Generally speaking, our data seem to be in line with the emerging trend in the literature, whereby certain personality traits, such as (E) and (A), predict the development of more adaptive coping strategies, characterized by problem orientation and support [23, 25]. Very interestingly, the association between personality traits and adaptive coping strategies seems stronger in the S-ID sample. This seems to be in accordance with the meta-analysis of Connor-Smith and Flachsnart [25], which identifies a stronger association between personality traits and coping strategies in more stressed samples. A view that we share with other authors [5, $10-13]$ is that growing up with siblings with disabilities can be a source of stress, and this can be significant in the development of siblings with typical development. It is in the relationship with a brother or sister with disabilities that a sibling with typical development can increasingly find himself or herself dealing with problematic and stressful situations in an interpersonal relationship. Appropriate coping strategies in this context are important to promote the better psychological adaptation of the individual. Certain personality traits promote more appropriate coping strategies, and this can reduce the risk of distress in individuals. In fact, according to some authors, it is possible that individuals with dysfunctional personality traits are at greater risk of stress due to the use of maladaptive coping strategies. In this way, relationships with brothers and sisters contribute to the development of their personality traits and the development of coping strategies. In particular, a positive relationship with brothers and sisters, characterized by low conflict and high levels of closeness and affection, seems to predict personality traits such as extraversion and openness [4] and more adaptive coping strategies $[5,10,14,18]$. However, as far as we are aware, this was the first study to test the moderating role of the quality of the relationship with brothers and sisters between personality traits and coping strategies in individuals raised with typical development siblings and siblings with disabilities. Our data confirm a possible moderating role of the quality of the relationship with brothers and sisters among the constructs investigated, both in the S-ID and S-TD samples. As highlighted in the results section of this article, the moderation role has differences and similarities between S-IDs and S-TDs; however, the theoretical reflections and empirical data available to us on the subject are scarce in terms of conducting a more precise interpretation of the results obtained. In general, we can argue that the quality of the relationship with brothers and sisters, based on its characteristics of affectivity, conflict, or rivalry, significantly influences the relationship between personality traits and coping strategies, particularly in the context of a relationship with a sibling with disabilities. Thus, our data support the idea that the quality of the relationship with siblings promotes the development of the individual, and the relationship with a brother or sister with disabilities can influence the development of individuals differently than that with a brother or sister with typical development. According to ours, the quality of the relationship with brothers and sisters, in its aspects of closeness, conflict, or rivalry, is not only associated with personality traits and coping strategies but also moderates the relationship, placing differences in the relational context with the brother or sister with intellectual disability and those with typical development. Our data, therefore, support the importance of the quality of the relationship with siblings and indicate the need for further investigation. In addition, from a clinical point of view, the quality of the relationship with siblings, particularly when there is a brother or sister with disabilities, can become the subject of psychological intervention to promote the greater adaptation of individuals and to increase closeness to siblings with disabilities in adulthood.

\section{CONCLUSION}

Despite the novelty of our contribution, some limitations presented by the study need to be taken into account. First, the cross-sectional approach adopted here limits us to interpreting causal relationships between the variables investigated, and, therefore, longitudinal studies are required to understand causal relationships between constructs. The study used self-reporting tools, and, therefore, factors related to text comprehension or social desirability may have intervened. Future studies may use different tools to measure the same constructs or use other observations. Finally, in this study, some variables were not considered, such as the age and birth order of the siblings, or the characteristics associated with the disabilities of the brother 
or sister, such as the type and degree of the impairment; his or her level of independence; or the presence of behavioral disorders. Future research may be extended to include some of these variables.

\section{ETHICS APPROVAL AND CONSENT TO PARTI- CIPATE}

The study was approved by the IRB of the University of Turin, Italy (protocol no. 47504).

\section{HUMAN AND ANIMAL RIGHTS}

Not applicable.

\section{CONSENT FOR PUBLICATION}

Informed consent was obtained from all individual participants included in the study.

\section{AVAILABILITY OF DATA AND MATERIALS}

The data that support the findings of this study are available from the corresponding author, [C.L] upon request.

\section{FUNDING}

None.

\section{CONFLICT OF INTEREST}

The authors declare no conflict of interest, financial or otherwise.

\section{ACKNOWLEDGEMENTS}

Declared none.

\section{REFERENCES}

[1] Cicirelli VG. Sibling relationships throughout the life cycle. The handbook of family psychology and therapy 1985; 1: 177-214.

[2] Cicirelli VG. Sibling relationships in cross-cultural perspective.Sibling relationships across the life span. Boston, MA: Springer 1995; pp. 69-85.

[http://dx.doi.org/10.1007/978-1-4757-6509-0_6]

[3] Sommantico M, Donizzetti AR, Parrello S, De Rosa B. Predicting young adults' Romantic relationship quality: Sibling ties and adult attachment styles. J Fam Issues 2019; 40(5): 662-88. [http://dx.doi.org/10.1177/0192513X18820381]

[4] Murray LE, O'Neill L. Neuroticism and extraversion mediate the relationship between having a sibling with developmental disabilities and anxiety and depression symptoms. J Affect Disord 2019; 243: 232-40.

[http://dx.doi.org/10.1016/j.jad.2018.09.042] [PMID: 30248634]

[5] Prino LE, Scigala D, Fabris MA, Longobardi C. The moderating role of gender in siblings of adults with intellectual disabilities. Interpersona 2019; 13(1): 1-13

[http://dx.doi.org/10.5964/ijpr.v13i1.323]

[6] Riggio HR. Measuring attitudes toward adult sibling relationships: The Lifespan Sibling Relationship Scale. J Soc Pers Relat 2000; 17(6): 707-28.

[http://dx.doi.org/10.1177/0265407500176001]

[7] Buist KL, Deković M, Prinzie P. Sibling relationship quality and psychopathology of children and adolescents: a meta-analysis. Clin Psychol Rev 2013; 33(1): 97-106.

[http://dx.doi.org/10.1016/j.cpr.2012.10.007] [PMID: 23159327]

[8] Conger KJ, Little WM. Sibling relationships during the transition to adulthood. Child Dev Perspect 2010; 4(2): 87-94.

[http://dx.doi.org/10.1111/j.1750-8606.2010.00123.x] [PMID: 20700389]

[9] Longobardi C, Gastaldi FGM, Prino LE, Pasta T, Settanni M.
Examining student-teacher relationship from students' point of view: Italian adaptation and validation of the young children's appraisal of teacher support questionnaire. Open Psychol J 2016; 9(1)

[http://dx.doi.org/10.2174/1874350101609010176]

[10] Orsmond GI, Seltzer MM. Siblings of individuals with autism or Down syndrome: effects on adult lives. J Intellect Disabil Res 2007; 51(Pt 9): 682-96.

[http://dx.doi.org/10.1111/j.1365-2788.2007.00954.x]

[PMID: 17845237]

[11] Orsmond G I, Kuo H Y, Seltzer M M. Siblings of individuals with an autism spectrum disorder: Sibling relationships and wellbeing in adolescence and adulthood. Autism 2009; 13(1): 59-80. [http://dx.doi.org/10.1177/1362361308097119]

[12] Prino LE, Pasta T, Gastaldi FGM, Longobardi C. The Effect of Autism Spectrum Disorders, Down Syndrome, Specific Learning Disorders and Hyperactivity and Attention Deficits on the Student-Teacher Relationship. Electron J Res Educ Psychol 2016; 14(1): 89-106.

[http://dx.doi.org/10.14204/ejrep.38.15043]

[13] Wilson CJ, McGillivray JA, Zetlin AG. The relationship between attitude to disabled siblings and ratings of behavioural competency. $\mathrm{J}$ Intellect Disabil Res 1992; 36(Pt 4): 325-36.

[http://dx.doi.org/10.1111/j.1365-2788.1992.tb00531.x] [PMID: 1388076]

[14] Jones EA, Fiani T, Stewart JL, Sheikh R, Neil N, Fienup DM. When one sibling has autism: adjustment and sibling relationship. J Child Fam Stud 2019; 28(5): 1272-82.

[http://dx.doi.org/10.1007/s10826-019-01374-z]

[15] Longobardi C, Prino LE, Gastaldi FGM, Jungert T. Sibling relationships, personality traits, emotional, and behavioral difficulties in autism spectrum disorders. Child Dev Res 2019; 2019: 1-9. [http://dx.doi.org/10.1155/2019/9576484]

[16] Burbidge J, Minnes P. Relationship quality in adult siblings with and without developmental disabilities. Fam Relat 2014; 63(1): 148-62. [http://dx.doi.org/10.1111/fare.12047]

[17] Doody MA, Hastings RP, O'Neill S, Grey IM. Sibling relationships in adults who have siblings with or without intellectual disabilities. Res Dev Disabil 2010; 31(1): 224-31.

[http://dx.doi.org/10.1016/j.ridd.2009.09.007] [PMID: 19819671]

[18] McCrae RR, Costa PT Jr. Personality, coping, and coping effectiveness in an adult sample. J Pers 1986; 54(2): 385-404. [http://dx.doi.org/10.1111/j.1467-6494.1986.tb00401.x]

[19] Carver CS, Scheier MF, Weintraub JK. Assessing coping strategies: a theoretically based approach. J Pers Soc Psychol 1989; 56(2): 267-83. [http://dx.doi.org/10.1037/0022-3514.56.2.267] [PMID: 2926629]

[20] Sica C. Magni; C., Ghisi; M., Altoé, G.; Sighinolfi, C.; Chiri, L. R.; Franceschini, S. Coping Orientation to Problems Experienced-Nuova Versione Italiana (COPE-NVI): Uno strumento per la misura degli stili di coping. Psicoter Cogn Comport 2008; 14(1): 27-53.

[21] Bolger N. Coping as a personality process: a prospective study. J Pers Soc Psychol 1990; 59(3): 525-37.

[http://dx.doi.org/10.1037/0022-3514.59.3.525] [PMID: 2231283]

[22] Bolger N, Zuckerman A. A framework for studying personality in the stress process. J Pers Soc Psychol 1995; 69(5): 890-902. [http://dx.doi.org/10.1037/0022-3514.69.5.890] [PMID: 7473036]

[23] Afshar H, Roohafza H R, Keshteli A H, Mazaheri M, Feizi A, Adibi P. The association of personality traits and coping styles according to stress level. Journal of research in medical sciences: The official journal of Isfahan University of Medical Sciences 2015; 20(4): 353.

[24] Barańczuk U. The five factor model of personality and emotion regulation: A meta-analysis. Pers Individ Dif 2019; 139: 217-27. [http://dx.doi.org/10.1016/j.paid.2018.11.025]

[25] Connor-Smith JK, Flachsbart C. Relations between personality and coping: A meta-analysis. J Pers Soc Psychol 2007; 93(6): 1080-107. [http://dx.doi.org/10.1037/0022-3514.93.6.1080] [PMID: 18072856]

[26] David JP, Suls J. Coping efforts in daily life: Role of big five traits and problem appraisals. J Pers 1999; 67(2): 265-94.

[http://dx.doi.org/10.1111/1467-6494.00056] [PMID: 10202805]

[27] O'Brien TB, DeLongis A. The interactional context of problem-, emotion-, and relationship-focused coping: the role of the big five personality factors. J Pers 1996; 64(4): 775-813.

[http://dx.doi.org/10.1111/j.1467-6494.1996.tb00944.x] [PMID: 8956513]

[28] Hooker K, Frazier LD, Monahan DJ. Personality and coping among caregivers of spouses with dementia. Gerontologist 1994; 34(3): 386-92.

[http://dx.doi.org/10.1093/geront/34.3.386] [PMID: 8076881]

[29] Caprara G V, Barbaranelli C, Borgogni L, Vecchione M. BFQ-2: 
manuale. Italy: OS: Firenze 2007.

[30] Caprara GV, Barbaranelli C, Borgogni L, Perugini M. Big five questionnaire. Firenze: OS Organizzazioni Speciali 1993.

[31] Stocker CM, Lanthier RP, Furman W. Sibling relationships in early adulthood. J Fam Psychol 1997; 11(2): 210-21. [http://dx.doi.org/10.1037/0893-3200.11.2.210]

32] Tani F, Guarnieri S, Ingoglia S. The Italian adaptation and validation of the Adult Sibling Relationship Questionnaire (ASRQ) in Italian emerging adults. TPM Test Psychom Methodol Appl Psychol 2013; 20(1): 47-67.

[http://dx.doi.org/10.4473/TPM20.1.4]

\section{(C) 2020 Scigala et al.}

This is an open access article distributed under the terms of the Creative Commons Attribution 4.0 International Public License (CC-BY 4.0), a copy of which is available at: (https://creativecommons.org/licenses/by/4.0/legalcode). This license permits unrestricted use, distribution, and reproduction in any medium, provided the original author and source are credited. 